\title{
Basilar Invagination: Transoral Microsurgical Endoscopically-Controlled Odontoidectomy without Palatotomy in Extreme form of Basilar Invagination
}

\author{
Hischam Bassiouni ${ }^{1}$ \\ ${ }^{1}$ Departments of Neurosurgery, Klinikum Amberg and Klinikum \\ Weiden, Bavaria, Germany \\ J Neurol Surg B 2021;82(suppl S1):S4-S5.
}

Address for correspondence Hischam Bassiouni, MD, PhD, Departments of Neurosurgery, Klinikum Amberg and Klinikum Weiden, Mariahilfbergweg 7, 92224 Amberg, Bavaria, Germany (e-mail: hibassiouni@yahoo.de).

\begin{abstract}
Keywords

- basilar invagination

- skull base

- transoral approach

- endoscopy

- odontoidectomy

Objective Transoral odontoidectomy in the treatment of basilar invagination is surgically challenging. Incision of the soft palate significantly increases rostral exposure of the clivus but is associated with a high incidence of speech and swallowing difficulties after surgery. We present a patient suffering from severe compression of the medulla oblongata due to an extreme form of basilar invagination treated successfully with the resection of dens via a transoral nasopharyngeal approach without palatotomy.

Setting Microsurgical endoscopic-assisted odontoidectomy through a transoral epipharyngeal approach was performed with subsequent craniocervical stabilization in a 21-year-old patient suffering from progressive myelopathy due to compression of the medulla oblongata and associated progressive syringomyelia.

Results The 21-year-old man was initially treated with suboccipital craniotomy and duroplasty in another institution. After initial improval he subsequently developed progressive ataxia, dysphagia, a bulbar speech, and weakness of the extremities. Beside ventral compression, he developed a secondary Chiari's malformation and a holospinal syringomyelia. Resection of the dens was successfully accomplished via a microsurgical transoral epipharyngeal endoscopic-controlled odontoidectomy without palatotomy. One week after odontoidectomy, posterior craniocervical stabilization was performed. All preoperative symptoms and signs improved significantly and the patient leads an independent life 4 years after odontoidectomy. On follow-up magnetic resonance imaging (MRI), the syringomyelia completely resolved.

Conclusions Palatotomy with its potential adverse effects can usually be avoided even for the treatment of extreme forms of basilar invagination.

The link to the video can be found at: https://youtu.be/CBKE4n94W4g.
\end{abstract}

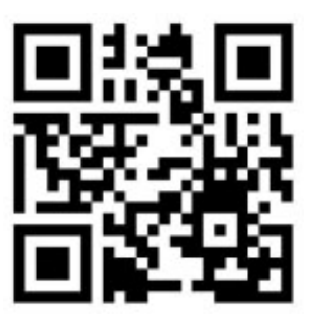

received

March 24, 2019 accepted after revision September 29, 2019 published online March 20, 2020

\author{
Conflict of Interest \\ None declared. \\ www.thieme.com/skullbasevideos \\ www.thieme.com/jnlsbvideos
}

DOI https://doi.org/ 10.1055/s-0040-1701216. ISSN 2193-6331.

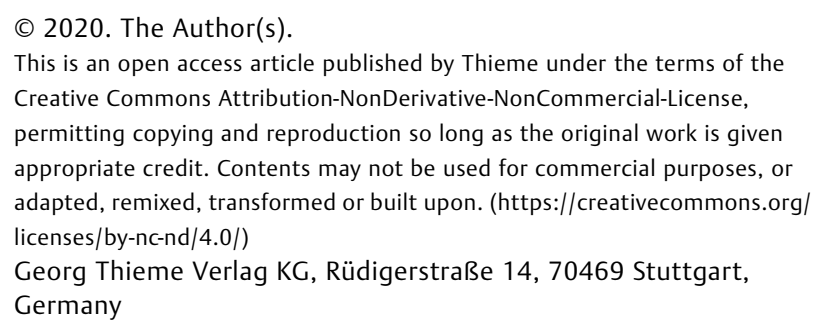




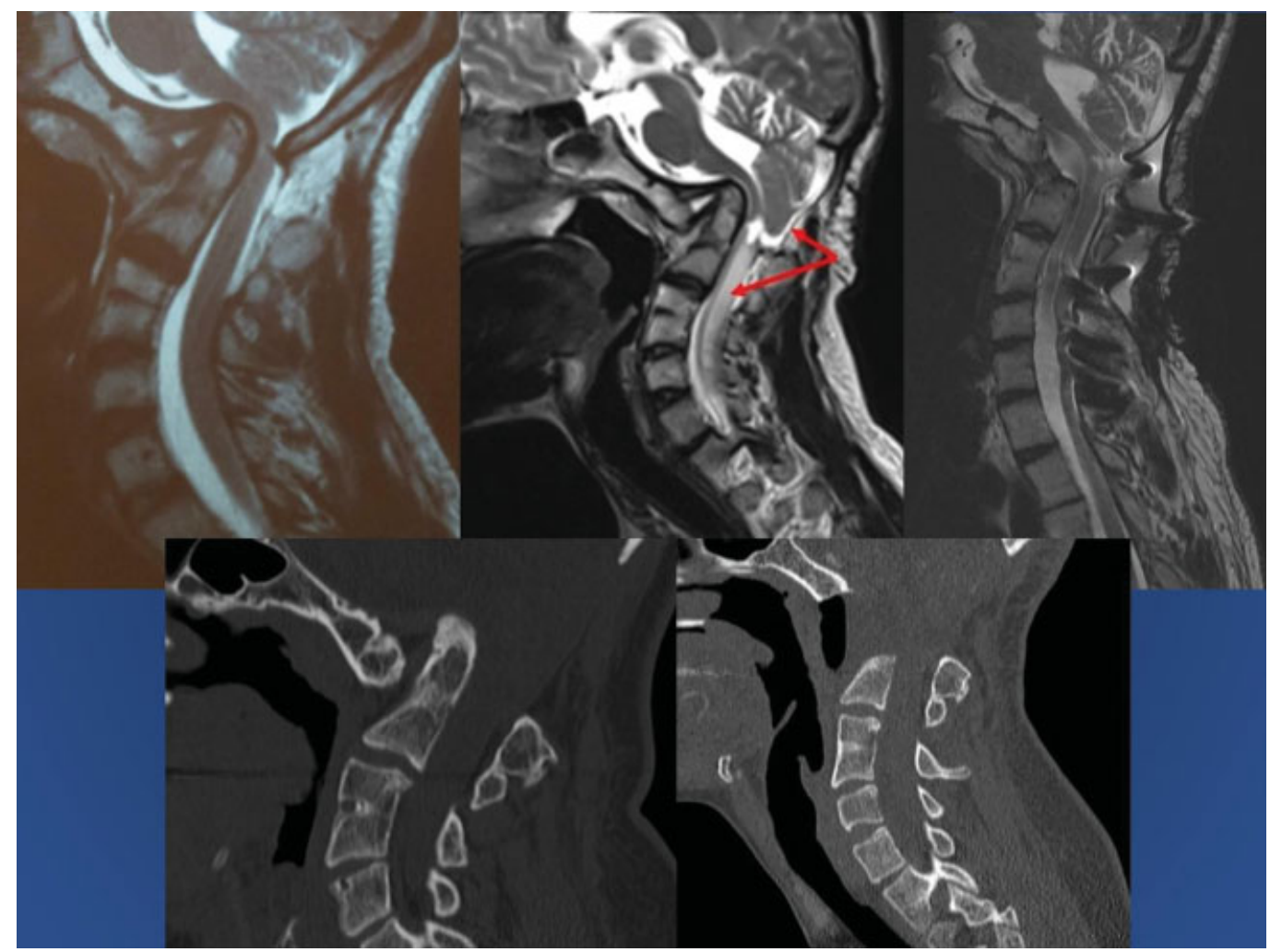

Fig. 1 Upper row: initial MRI displaying basilar invagination with lower brainstem compression; MRI after suboccipital decompression in another institution showing secondary syringomyelia; and MRI after odontoidectomy with brainstem decompression and craniocervical stabilization. Lower row: bone window CT scan before and after odontoidectomy. MRI, magnetic resonance imaging.

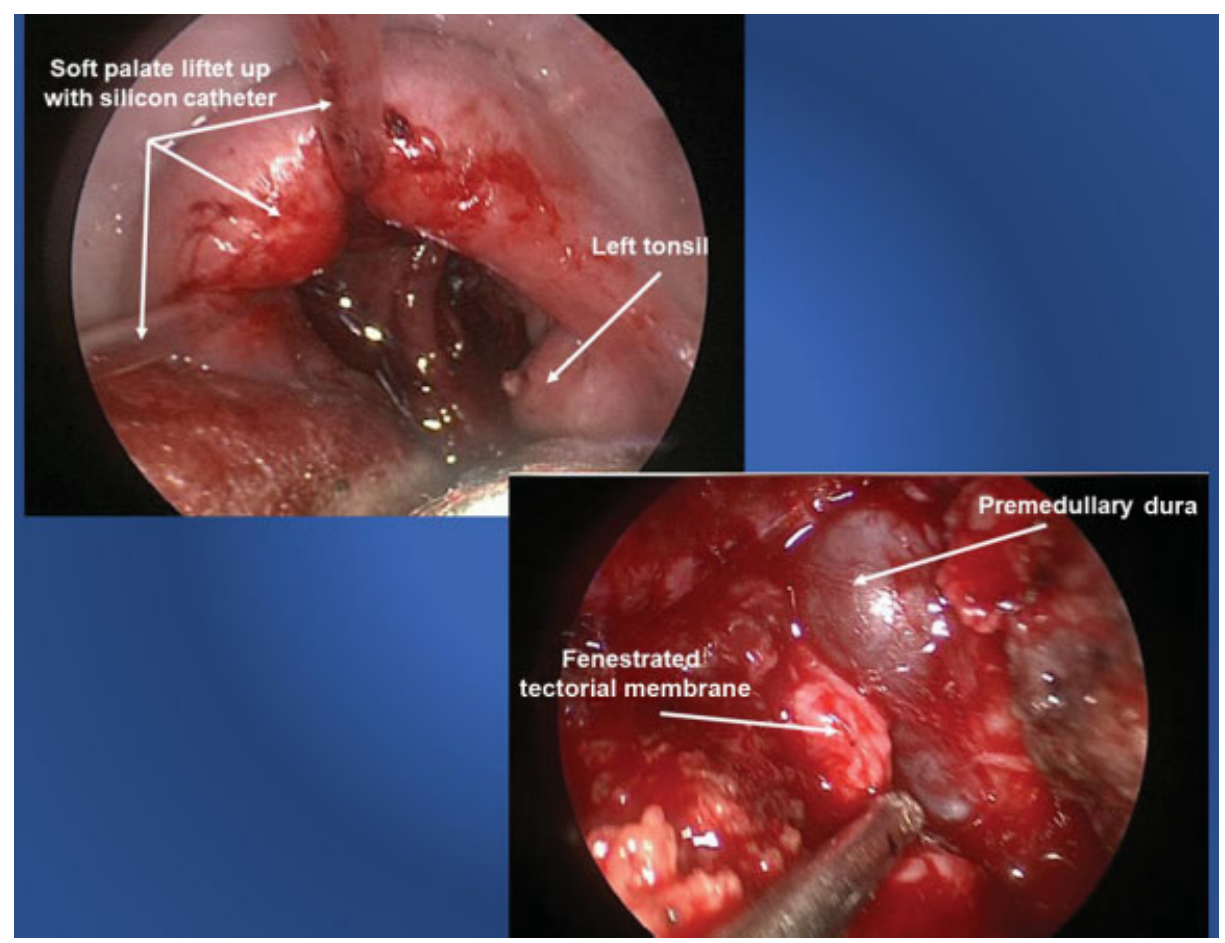

Fig. 2 Endoscopic intraoperative control demonstrating transoral epipharyngeal approach with soft palatal preservation and decompression of the brainstem after odontoidectomy. 